\title{
The Discovery Camp: A Talent Fostering Initiative for Developing Research Capabilities among Undergraduate Students
}

\author{
Joerg Evermann, Val Hooper, Pak Yoong, \\ Janet Toland, and Eusebio Scornavacca \\ School of Information Management, Victoria University of \\ Wellington, Wellington, New Zealand
}

\author{
jevermann@mcs.vuw.ac.nz; val.hooper@vuw.ac.nz; \\ pak.yoong@vuw.ac.nz; janet.toland@vuw.ac.nz; \\ eusebio.scornavacca@vuw.ac.nz
}

\begin{abstract}
As universities become increasingly research driven and funded on a research-basis, there is an increased need to attract graduate research students. The easiest way of doing this is to draft highly-talented undergraduate students into the research programmes. However, in a booming industrial job market, this is no easy task for Information Systems and Information Technology programmes. Recognizing that it is easier to retain than to recruit, the School of Information Management conducted an event to foster talent among students and garner interest in the graduate programmes of the school. This paper reports on the experiences of the staff members conducting the event.
\end{abstract}

Keywords: Graduate studies, Student retention, Research degree, Talent fostering

\section{Introduction}

One of the critical success factors for a university is its ability to sustain a rich and vibrant research environment. This factor is often demonstrated by a regular listing of high quality research-based publications, a steady stream of completed $\mathrm{PhD}$ theses and the offerings of postgraduate courses that facilitate the development of such research skills. However, in order to achieve these goals, a university also has to recruit high achieving undergraduate students who can be inspired to move on to commence post-graduate research-based studies. So the key question is this: What can a university do to attract and inspire these budding researchers to consider moving on to post-graduate research-based courses? This paper describes an initiative developed by a university department that aims to engage high achiever undergraduate students in small

Material published as part of this publication, either on-line or in print, is copyrighted by the Informing Science Institute. Permission to make digital or paper copy of part or all of these works for personal or classroom use is granted without fee provided that the copies are not made or distributed for profit or commercial advantage AND that copies 1) bear this notice in full and 2) give the full citation on the first page. It is permissible to abstract these works so long as credit is given. To copy in all other cases or to republish or to post on a server or to redistribute to lists requires specific permission and payment of a fee. Contact Publisher@InformingScience.org to request redistribution permission. scale collaborative research projects and through these experiences inspire them to move on to graduate study.

The School of Information Management (SIM) at Victoria University of Wellington has one of the highest student enrolments in undergraduate courses in the university. The two main directions of the SIM courses are Information Sys- 
tems (INFO) and Electronic Commerce (ELCM).

Despite the high undergraduate numbers, the throughput percentage to postgraduate Honours (Hons) study is very small. In addition, with the generally large classes, lecture and tutorial presentations tend to be pitched towards the slightly-above-average student, rather than at the top students. It is thus a challenge to stimulate the latter while aiming to motivate the rest of the class to higher academic achievement. Various interested and concerned staff members had held informal discussions about this but a more formal, coordinated and directed approach was needed.

The SIM Talent Fostering initiative was thus established as a coherent set of systems and processes to foster student talent (Gandz, 2006). The initial steering group comprised six staff members and the Director of the Undergraduate Programmes - all acting on a voluntary basis. The overriding goal of the initiative is to attract top quality students and nurture them through their undergraduate years so that they develop a passion for information systems (IS) and various aspects of the discipline, including research. As a result, a good potential class of honours students should emerge - or enthusiastic practitioners with strong bonds to the school.

A number of sub-initiatives to realize the goal were identified:

- A discovery camp for talented undergraduate students

- A boot camp for talented high school students in their final year.

- A young scientist research mentoring programme

- Awards for top achievers in INFO and ELCM 300-level courses

- Arrangements of internships with local industry

- Conducting exeunt focus group interviews with final year students not pursuing graduate studies

- Ongoing customer relationship management with undergraduate students

- Establishment of informal groups nurturing international and Maori/Pacific Island students

These would be planned to occur at different times of the year, with the Discovery Camp being the first specific event.

This paper reports on the first of the listed events and proceeds as follows. Section 2 briefly reviews existing literature. Section 3 presents the objectives and organization of the event, followed by experience reports in Section 4. Section 5 reflects on the experiences and Section 6 concludes the paper with a discussion of the experience.

\section{Prior Literature}

Talent development has been recognized as an important activity for businesses (Gandz, 2006). While the aim in the event presented here was to develop candidates for graduate studies, the techniques of talent development in business remain applicable. Gandz (2006) proposes four necessary conditions. First, a clear picture of talent requirements must be established. The school has done this through its strategic vision where graduates, as well as being academically successful, display attributes of leadership, critical thinking and communication skills. Second, Gandz (2006) suggests defining experiences and challenges by which talented performers can be identified. The objectives and structure of the discovery camp, outlined below, are designed with this in mind. As a third requirement, Gandz (2006) proposes that key administrative systems and processes must be in place to support talent development. In the previous section, we have outlined that the dis- 
covery camp is part of a larger set of such events and processes to foster talent. Finally, Gandz (2006) recommends action learning and a focus on values and competencies for the specific talent development events. The discovery camp was designed to highlight the values of inquisitiveness and proactivity, while also emphasizing research and critical thinking skills.

A second aspect in which the discovery camp is based on established principles is in the style of learning. Collaborative learning suggests that learning is not so much passive receiving of information but active building of minds (Barkley et al., 2005). Consequently, students must be led to discovery, rather than being presented with facts or lectured to. Moreover, while cooperation and teamwork among students is important (Ketteridge et al., 2002), learning can be further enhanced by encouraging contact between students and faculty (Chickering and Ehrmann, 1996). Other success factors of teaching are a desire of faculty to share the love of the subject with students, establish intellectual challenges, and encourage confrontation of students with different ideas (Ramsden, 2003). The structure of the discovery camp, described below, is based on these principles of guided group tutoring.

\section{The Discovery Camp}

\section{Discovery Camp Objectives}

The discovery camp was conceived as an event within the context and programme outlined in Section 1, as part of a larger talent development programme (Gandz, 2006). Its primary aim was to foster interest in the school's graduate degree programmes. Secondary objectives of the event included recognition of student performance in their degree programmes, ensuring their continued performance, identifying students suitable for research assistant roles, and ensuring students remain committed to degree programmes offered by the school.

The school's graduate degree programme is research focused. In light of this, the discovery camp was to present an opportunity for students to learn about research and engage in some practical research activities. As the research aspect of the school is not evident in the undergraduate curriculum (i.e. there are no research based courses), this would present a challenge to students and it was hoped that by accepting this challenge students would show both their capability and interest. Offering a brief "preview" of the research based graduate programme was hoped to raise initial interest in students to consider this option for their future career plans. However, at the same time, the event would have to remain an enjoyable social function, in order not to overwhelm participants with work or minute details. Thus, a fine balance was to be achieved. These objectives also gave the event its name, the emphasis being on research (discovery) and an enjoyable time (camp).

By means of inviting students to the event, rather than students applying for the event, the school wanted to demonstrate that students' academic achievements were recognized and their sustained performance had differentiated them from peers. To further emphasize this point, the event was limited to a small number of 20 students. Although it would have been desirable to attract as many students as possible to pursue post-graduate study, it was decided to initially focus on nurturing quality rather than quantity. This also meant availing the students of the opportunity to receive personal attention from the faculty.

A third objective of the event was to foster student-faculty interaction, part of good teaching and learning (Chickering and Ehrmann, 1996), with the aim of identifying capable students that may be recruited for other roles, primarily research assistants, but also tutoring roles within the school. For this type of recruitment, it is necessary to identify student's strengths, areas of interests, social abilities and communication skills. It was hoped that an informal, social exchange between stu- 
dents and faculty would help the school and individual faculty identify suitable candidates for those roles.

Finally, most of the school's undergraduate students pursue degree programmes where only one major field of study was within the school (information systems or electronic commerce), while another major is either within the same faculty, but often also found with another faculty (such as computer science or teaching majors). Therefore, it was not only necessary to ensure continued academic performance and interest in research based graduate studies, but this needed to be coupled with a specific interest in information systems or electronic commerce.

\section{Discovery Camp Organization}

The discovery camp was held on the Friday and Saturday morning of the first week of a twoweek mid-term break in the second semester of the year. The date was chosen to allow time to survey first semester grades and not have to rely solely on previous years' grades. It was earlier than the usual time for graduate studies recruitment events, as past experience has shown that students would often have accepted industry jobs by that time. Finally, placing it in the middle of the mid-term break signalled the distance to regular classes and learning that was necessary to position this as a special event, outside and beyond the ordinary curriculum, for high-achieving students.

Based on the interests and expertise of the participating faculty, the theme for the discovery camp was chosen to be "Online Social Networking (OSN)". Within this theme, students could identify more specific topics of interest to themselves.

The event was organized with the structure of an academic conference, in sessions of 1.5 hours. The first session included registration, a welcome from the head of school, and a keynote address, given by a current graduate student who related his personal experiences in graduate studies. The keynote emphasized the aspect of discovering new knowledge, while at the same time focusing on the fun aspects of social interaction amongst graduate students and faculty, and the academic freedom in graduate studies. Half-hour long coffee breaks between sessions provided time for socializing. The second session included a half-hour introduction to the theme of the discovery camp and suggested possible topics of interest within this theme. Participating faculty members introduced themselves and presented their research interests, current projects and their specific interest in the theme of the event.

For the remaining sessions, students were randomly assigned to small groups to work with a faculty member in break-out rooms. Only general outcomes of the remaining sessions were agreed upon, leaving the faculty members and the individual groups freedom to work with different approaches (see Section 4). Faculty members played the roles of tutors and guides, rather than teachers or lecturers (Barkley et al., 2005; Ketteridge et al., 2002).

The first afternoon session was intended to introduce elements of the research process. At the end of this session, groups should have agreed upon an initial research question and initial idea of research method to investigate this question. At the end of the session, all groups would gather and briefly present their research question and the process by which they had arrived at it.

The outcome of the second afternoon session was an initial research instrument to fit the research question. Again, the groups would gather and briefly present their outcome and process of that session. All instruments were collected, photocopied, and distributed to all participants to be completed as "homework" overnight.

The first session of the second day involved each group analysing the collected data and developing a presentation to the entire group. These presentations filled the second session, offering each group 20 minutes to present their results, and their experiences of the two days. 
While the event was introduced to students as a recognition of their academic achievements and an opportunity to explore issues beyond their undergraduate curriculum and the relationship to graduate studies was de-emphasized, some participants felt that the overall event was a graduate recruitment. In order to address this issue, the closing of the event included three addresses. First, the school's undergraduate director emphasized the fact that the event was to recognize student achievement. The school's graduate programme director then briefly introduced the specifics of the school's graduate programme. Finally, a brief closing address by the head of school again emphasized the achievements of the invited participants and gave out certificates of recognition.

\section{The Research Project Groups}

Groups consisted of three to five students and were colour coded randomly. This section retells the subjective experiences of the faculty members. Hence, it is written in each faculty members' individual style to retain the richness of the experiences for the reader.

\section{Orange Group}

This group consisted of five students. The two second year students both majored in e-commerce and psychology. One third-year student majored in accounting and IS, the other in e-commerce and IS. The final student had previously completed a computer science degree and now majored in IS.

The approach taken avoided technical terms, such as "validity", "reliability", or "research question". This was not done to deceive participants but instead to make them feel more at ease and emphasize the informal nature of the event. Moreover, in the spirit of "discovery", students were not guided but rather encouraged to discuss and discover good research practice. For example, the faculty member initiated a discussion about the qualities of a good "discovery" question. Students were guided to see the benefits of research questions that are new, interesting, and relevant and topics that are neither too broad nor too narrow. The group discussed how these attributes of research questions can manifest themselves and can be evaluated. While the group had only developed an initial question at the end of the first session, the students felt that the process of arriving at this question and discussing the various aspects provided valuable insight into the finer details of research and showed that even asking the right question is a challenge.

During the second session, the group briefly discussed different research methods, but quickly converged on quantitative questionnaires. The faculty member then guided the discussion towards instrument design. Among other things, the group discussed the properties of a good questionnaire item, e.g. that it should be unambiguous, that it should not require guesswork, that it should refer to a precise event and a representative time period for which subjects still have recall. Discussion also touched on notions such as convergent and discriminant validity, and reliability. However, the technical terminology was not introduced. For example, the group discussed how one could ensure that the questionnaire would always yield an accurate good measurement, and how one can ensure that every question only measures one thing. The outcome was only an initial draft of a questionnaire, but students felt the discussion of these issues was a valuable learning experience.

The first session on the second day focused on data analysis techniques. The group discussed statistical techniques, such as data plotting, regression, standard deviations and confidence intervals, and a simple t-test. However, these were discussed conceptually, and no actual computations were performed. Participants felt that this was worthwhile experience and preferred it to spending their time entering data into statistics software.

As a result of this, the final group presentation centred on the process by which the outcomes of each session were arrived at, rather than any actual discoveries or results. Again, the students re- 
ported that valuable learning had occurred, and their feedback on the event was in line with that of students of other groups.

\section{Blue Group}

The first group session focused on determining a topic of exploration. After initial introductions and getting to know a bit about one another, the first step was to alert the group members to the need to think of a name for the group. While it could only be decided once the group members had some measure of the group character, they needed to be mindful of this eventual requirement. This would serve to bind the group - by focusing on the group character, rather than individual characteristics. A name is also a very important identifying and relational feature and would assist in bonding.

The next step was to decide on a topic to explore, related to the overall theme of 'social networking'. The group members launched enthusiastically into discussions. It soon became clear that they were particularly interested in different aspects of social relationships - the impact of different technologies, the impact on quality vs quantity, the impact on different types of relationships, and ethical considerations. In these discussions the faculty member acted as facilitator, encouraging each member to contribute, and encouraging the group to tease out the different aspects of each suggested option. Appropriate scoping and careful definition of the topic presented quite a challenge to the group members. Once the options had been finalized, the group made a decision by means of a Delphi technique (Schmidt, 1997). The merits of such decision making were explained to the group so that they could understand the underlying rationale. The identified topic was "The impact of selected communication technologies on social relationships".

Because of the limited time available to conduct their research, the group was alerted to how it would impact on the exercise in terms of what could, and what could not, be done. Bearing that in mind, each session would have a target goal to achieve in terms of output, and that would guide the developments of each session. A further point that was explained was the role of the human ethics process of the University, and its guidelines regarding research involving humans.

The following session focused on deciding how the research question could best be addressed within the constraints of the Discovery Camp. It was decided that a survey would be the most effective and efficient method. The principles of questionnaire construction were briefly explained and the group then set about compiling their questionnaire. Concepts such as scaling, open and closed-ended questions, branching, ambiguity, question phrasing, and sequencing were covered. One of the biggest challenges for the group was to remain focused on the research question and to ensure that each questionnaire item contributed to addressing it. By the end of a very intensive session in which all members contributed in a lively fashion, a questionnaire had been produced. This was then copied and sent home with each Discovery Camp participant for overnight completion.

The next day saw the group analysing the questionnaire responses. A simple coding system was explained and the task of coding the answers was divided between the group members. An issue which arose was the provision of multiple answers to a question when only one had been required. Although easily dealt with, this provided an opportunity to emphasize the care needed in questionnaire construction and also the necessity of pretesting an instrument.

Once all responses had been recorded and aggregated, the communications technologies which had had the most positive impact on the six categories of relationships, and those that had had the most negative impacts were identified. Then the comments pertaining to those technologies were perused by the group - 4 to 5 questionnaires per member - and pertinent quotes selected. The impact of the quotes in bringing the analysis to life and making it more credible was emphasized. Finally, the findings were consolidated, the implications discussed by the group and the research 
exercise recorded and prepared for presentation to the Discovery Camp in the last session. Each group member selected a task to perform in these final stages.

As a matter of interest, it transpired that the communications technology with the most positive impact was mobile phone texting for all groups except for communicating with older family members, when e-mail was the most common - possibly because older people struggled to see the small mobile phone print. Although the general responses were that communications technologies did not have many negative impacts, mobile phone texting was identified as the more problematic in all relationships - particularly friends who sent messages in drunken states, as one respondent indicated.

And the name of the group was the 'Blueberries'.

\section{Black Group}

This was the smallest group, with only three student members, as a few of the invited students had not shown up. Despite its small size my group was well mixed in terms of gender and cultural background, we were two males and two females, and four different nationalities. I had taught one student on my undergraduate paper earlier in the year so I knew him fairly well; another member of the group had taken my course the previous year. The fact that we had these previous connections helped the group to have a relaxed atmosphere from the beginning. The first session was probably the most difficult one in terms of getting our ideas together. I did not want to force my ideas of what online social networking was on the group, as the idea was that they would come up with their own research question. However, my group did seem to be in broad agreement with the ideas about social networking that I had put forward to the whole class in the introductory session. One group member had experience of using the Flikr photograph sharing site, which gave us a useful example to base our discussions around. As we tried to brainstorm ideas, I felt that the small size of the group was a disadvantage; we could have really done with a few more people to get more input at this stage. Towards the end of the session we realised that time was running out, and that we quickly needed to decide on our research question. We came up with the research question, "Why do people use social networking Internet sites?", and decided to do a questionnaire survey, and also to search for statistical information online. One group member was particularly interested in the different reasons that people from different cultures might have for using social networking sites. That member felt that New Zealander's and Europeans would be more attracted by the idea of " 15 minutes of fame" than Asian students. We were interested to find out that the Asian member of the group was unaware of Andy Warhol's famous quotation, which illustrated the mistakes that one culture can make in assuming a certain set of common knowledge in other cultures.

After presenting back to the full group, we felt happy that we were pretty much on track with our presentation, and went back to the next session ready to make our questionnaires. This session was really tight for time! We had to work very fast to get a questionnaire together within the time limit. Our small size started to be an advantage here, as we didn't have any conflict and were able to keep on task well. We decided to collect some basic demographic information about gender, age and nationality of respondents. As our survey group was small (the rest of the participants in the Discovery Camp), I pointed out that we should be careful not to collect information that would enable us to uniquely identify any particular respondent, e.g. 45 year old European female. We asked students which social networking sites they were aware of, whether they were willing to share photographs online, whether they would rather watch music in the Internet or television, and what they though peoples motivations were for using social networking sites.

The session the following morning when we had to analyse the results also left us feeling time challenged. We split into two groups to prepare graphs, and pie charts to illustrate our results. We 
realised that we just didn't have time to analyse our data in all the ways we would have liked to, so we concentrated on cultural differences, though it would have been interesting to analyse differences between younger and older respondents as well. We had intended to look for statistics about the number of users that different social networking sites had to see if our respondents "fitted in" with the general trend. We did manage to get a few statistics, but basically we ran out of time to do this properly.

When we made our presentation I felt our group had worked really well and had some interesting results to show to the rest of the group. We could have spent more time discussing the strengths and weaknesses of our research methods, but basically once we had agreed on our research question we just got on with it, if we'd stopped to think too much about it we wouldn't have finished.

As some of the other groups made their presentations it became obvious that one of the major objectives of some of the group leaders had been to make sure their groups had fun, and there were some very entertaining presentations. I felt a bit sorry for my group as I hadn't really thought consciously about the "fun" aspect; I'd concentrated on the task and made them work very hard, though I think they mostly enjoyed it. If I ran a group again this is the one area I would work on to try to improve the experience of the students.

\section{Green Group}

\section{Group introductions}

I had four students in my group, three females and a male. I already knew that one of the students was a member of my large $3^{\text {rd }}$ year course and found out that another student was brought up in Papua New Guinea, a country I have stayed in for 5 years. Therefore, I have immediate bonding with these two students. It did not take long for the other two to be included as part of our group as they knew each other in different contexts.

\section{Identify the research question}

I then spent 10 minutes going over the nature of academic research and the need to identify a research question and the gathering of data to answer that question. While in the process of identifying the research question, we each took turns to outline our personal interests in the area of online social networking (OSN). As it subsequently emerged, some of us were interested in the application of OSN in the education sector and others in the use of mobile technology to facilitate OSN. After a period of negotiations, we formulated a compromise question which dealt with the topic of mobile learning (m-learning), and subsequently agreed on this research question: "What are the facilitators and inhibitors of m-learning?"

\section{Data collection and analysis strategy}

As we were told that data collection should be confined among the members of the larger camp, we decided to make things easy for ourselves by designing a two-stage data collection and analysis strategy: (A) conduct a group brainstorming session to identify the key facilitators and inhibitors and (B) hold group interviews on a short list of key issues identified in Stage 1.

Stage A - Group brainstorming session:

During this session, we identified 18 facilitators and 12 inhibitors of m-learning. By combining similar factors, we subsequently created 7 major categories for both lists of facilitators and inhibitors. 


\section{Stage B-Individual interviews}

We then did a group interviewing (essentially a group discussion) of each category by elaborating or describing personal experiences of each category of the facilitators and inhibitors. Through this process, the group members developed a shared understanding of each major factor. As we went through this process, we also found out that we had also conducted an initial data analysis and the group then proceeded to refine the initial findings.

\section{Preparation for the group presentation}

One of the expectations of the camp was that each group was to present their group findings during a plenary session. Since our project used a qualitative research approach, we decided to use 'action role play' as our medium of presentation. The reasons for this choice were (a) to add a bit of fun in the presentation and (b) to illustrate via role plays some of the key factors of m-learning. We designed a scenario for each factor and then rehearsed a role play associated with that scenario.

\section{Role plays and audience participation}

We also decided to have audience participation during the presentation of the role plays. This was done by creating a checklist of each facilitator and inhibitor and we asked the audience to tick which factor was demonstrated during each role play. At the end of the presentation, we then gave the answers and ask the participants to check their respective answers.

\section{Reflections}

After the presentation during which we received very good feedback for our novel approach, we gathered as a smaller group and reflected on our experiences of the exercise. In general, we all felt that we have understood more what is involved while conducting an academic research project and that it could be fun as well. A dramatic shift of earlier perceptions, that academic research could be boring.

\section{Red Group}

\section{Session 1 - Research question}

The red group - know as the red brigade - consisted of four students. Three students were about 20 years old and the remaining participant was a mature student. During the round of introductions, each person (including the faculty member) talked about their background and expectations for this exercise. It was interesting to notice that all students were interested to learn - perhaps demystify - the types of activities that are involved in the process of doing research.

During the first session the group briefly shared their views of the Discovery Camp. Once the group achieved a common understanding of the topic, the faculty member talked about how to develop a research question and asked the students to identify the following items:

1) Who are we studying? People? Organizations?

- People, more specifically DC participants

2) What types of ICT are we interested to study?

- Mobile Phones

3) What is the connection of 1) DC participants and 2) Mobile Phones to the DC theme?

- People use of this type of technology to interact with Social Networks. 
The faculty member asked each student to write a few questions involving the three items identified above. The group engaged in a discussion aimed at converging to a research question that represented the group. The following question was developed:

- Why are people using mobile phones to interact with their social networks?

In addition, three sub-questions were also formulated:

- What applications are they using (e.g. SMS, MMS Internet)?

- How much are they using these applications?

- What is driving them to use this technology?

\section{Session 2 - Research method}

The group briefly discussed different ways to answer the research question. The faculty member briefly explained some qualitative and quantitative research methods. The group wanted to develop a two-phase study using focus group and questionnaire. However due the limited amount of time it was agreed that a questionnaire would be a more feasible choice.

The faculty member then guided a discussion towards the development of the survey instrument. The students had the opportunity to see two examples of questionnaires developed by the school's faculty. Also the faculty member presented to the students the "Theories in IS Research" website (http://www.istheory.yorku.ca/) where they could look at some models (e.g. TAM, TTF, UTAUT) to demonstrate that there are theories behind each item of the questionnaires.

The group then discussed the type of information they needed to collect. They decided to divide the questionnaire in four parts: 1) Demographic Information, 2) Mobile Phone details, 3) Use of Mobile Phone Applications and 4) Drivers of Mobile Phone Use.

This session seemed to have generated a valuable learning experience for the students. They were quite excited with the final process as well as the final product.

\section{Session 3 - Data analysis}

Before the beginning of the third session the group members carried out their data collection, distributing the questionnaire to the remaining event participants. Once the questionnaires were collected, the faculty member demonstrated to the students how to use a data analysis software. The students seemed to get quite excited about the perspective of learning how to use new software. Two students were in charge of inputting the data collected while the remaining two started to prepare the slides for the final presentation. The faculty member guided a discussion of what should be included in the presentation and demonstrated how to use PowerPoint. Once the data input was finished, the group got together to analyse data and complete the slides containing the survey results.

\section{Session 4 - Presentation}

The final presentation was shared among the four students. They presented their research question and objectives, described the methodology and the process of developing the questionnaire as well as the data collection and analysis. Finally they presented their findings and conclusions. In addition, they included a slide pointing out that the discovery camp was a valuable and inspirational learning experience. 


\section{Analysis of Group Processes}

Shortly after the Discovery Camp took place, the faculty members met to discuss the outcomes of the event. Each of the five group leaders reflected on how their colour group had worked. A summary of this is shown as Table 1.

All faculty began their work with the group with an "icebreaking" session. Generally, this consisted of getting students to introduce themselves. Each group had been randomly assigned a colour; the blue and red groups used their colours as a basis for choosing a group name that helped to develop bonds. The blue and red groups used the exercise of choosing their group names as a way of developing bonds.

Table 1: Summary of Group Processes

\begin{tabular}{|c|c|c|c|c|c|}
\hline & Orange & Blue & Black & Green & Red \\
\hline Introduction & $\begin{array}{l}\text { Established } \\
\text { background } \\
\text { details for each } \\
\text { student }\end{array}$ & $\begin{array}{l}\text { Choosing a } \\
\text { group name used } \\
\text { to develop iden- } \\
\text { tity }\end{array}$ & $\begin{array}{l}\text { Already taught } \\
\text { two students so } \\
\text { had pre- } \\
\text { established } \\
\text { bonds }\end{array}$ & $\begin{array}{l}\text { Already taught } \\
\text { one student, had } \\
\text { worked in home } \\
\text { country of an- } \\
\text { other student }\end{array}$ & $\begin{array}{l}\text { Established stu- } \\
\text { dent background } \\
\text { and expectations } \\
\text { for this exercise }\end{array}$ \\
\hline $\begin{array}{l}\text { Teaching } \\
\text { Strategy }\end{array}$ & $\begin{array}{l}\text { Discovery learn- } \\
\text { ing approach } \\
\text { Avoidance of } \\
\text { technical terms }\end{array}$ & $\begin{array}{l}\text { Faculty acted as } \\
\text { a facilitator } \\
\text { Encouraged all } \\
\text { members to con- } \\
\text { tribute }\end{array}$ & $\begin{array}{l}\text { Faculty held } \\
\text { back to let stu- } \\
\text { dents develop } \\
\text { their own ideas }\end{array}$ & $\begin{array}{l}\text { Guided discus- } \\
\text { sion }\end{array}$ & $\begin{array}{l}\text { Guided discus- } \\
\text { sion }\end{array}$ \\
\hline $\begin{array}{l}\text { Developing the } \\
\text { Research } \\
\text { Question }\end{array}$ & $\begin{array}{l}\text { Faculty initiated } \\
\text { a discussion } \\
\text { about "good" } \\
\text { research ques- } \\
\text { tions }\end{array}$ & $\begin{array}{l}\text { Used Delphi } \\
\text { technique to } \\
\text { make a decision }\end{array}$ & $\begin{array}{l}\text { Used a white- } \\
\text { board to brain- } \\
\text { storm potential } \\
\text { questions }\end{array}$ & $\begin{array}{l}\text { Took turns to } \\
\text { outline their } \\
\text { personal inter- } \\
\text { ests - negotiated } \\
\text { a compromise } \\
\text { solution }\end{array}$ & $\begin{array}{l}\text { Based on a brief } \\
\text { discussion stu- } \\
\text { dents wrote their } \\
\text { own questions } \\
\text { and negotiated } \\
\text { to converge in } \\
\text { one question }\end{array}$ \\
\hline $\begin{array}{l}\text { Research } \\
\text { Approach }\end{array}$ & $\begin{array}{l}\text { Questionnaire } \\
\text { survey }\end{array}$ & $\begin{array}{l}\text { Questionnaire } \\
\text { survey } \\
\text { Emphasised } \\
\text { ethics }\end{array}$ & $\begin{array}{l}\text { Questionnaire } \\
\text { survey }\end{array}$ & $\begin{array}{l}\text { Group brain- } \\
\text { storming \& in- } \\
\text { dividual inter- } \\
\text { views }\end{array}$ & $\begin{array}{l}\text { Questionnaire } \\
\text { survey }\end{array}$ \\
\hline Data Analysis & $\begin{array}{l}\text { Discussed good } \\
\text { questionnaire } \\
\text { design \& simple } \\
\text { statistical tech- } \\
\text { niques }\end{array}$ & $\begin{array}{l}\text { Discussed char- } \\
\text { acteristics of a } \\
\text { good question \& } \\
\text { simple coding } \\
\text { techniques. }\end{array}$ & $\begin{array}{l}\text { Short of time to } \\
\text { analyse data as } \\
\text { would have } \\
\text { liked to. } \\
\text { Emphasised } \\
\text { research ethics }\end{array}$ & $\begin{array}{l}\text { Two stage data } \\
\text { collection \& } \\
\text { analysis strategy } \\
\text { Action role play } \\
\text { used for presen- } \\
\text { tation }\end{array}$ & $\begin{array}{l}\text { Discussed ques- } \\
\text { tionnaire design } \\
\& \text { showed ex- } \\
\text { amples. Used } \\
\text { data analysis } \\
\text { software }\end{array}$ \\
\hline $\begin{array}{l}\text { Research } \\
\text { Outcome }\end{array}$ & $\begin{array}{l}\text { Concepts dis- } \\
\text { cussed but not } \\
\text { computed }\end{array}$ & $\begin{array}{l}\text { Usable results } \\
\text { consolidated } \\
\text { Some unex- } \\
\text { pected findings }\end{array}$ & $\begin{array}{l}\text { Some usable } \\
\text { results but not } \\
\text { as much depth } \\
\text { as hoped for }\end{array}$ & $\begin{array}{l}\text { Usable results } \\
\text { Novel, fun ap- } \\
\text { proach }\end{array}$ & Usable results \\
\hline $\begin{array}{l}\text { Emphasis on } \\
\text { Process or } \\
\text { Product }\end{array}$ & $\begin{array}{l}\text { Emphasis on } \\
\text { research process }\end{array}$ & $\begin{array}{l}\text { Emphasis on } \\
\text { research product }\end{array}$ & $\begin{array}{l}\text { Emphasis on } \\
\text { research product }\end{array}$ & $\begin{array}{l}\text { Emphasis on } \\
\text { research process }\end{array}$ & $\begin{array}{l}\text { Balance be- } \\
\text { tween both } \\
\text { process \& prod- } \\
\text { uct }\end{array}$ \\
\hline
\end{tabular}

Faculty had already agreed that they should act as tutors and guides, rather than lecturers or teachers, so all group leaders adopted similar teaching strategies, the emphasis was on a discovery 
learning approach and guided discussions. Faculty took on a facilitation role and "held back" with the aim of getting the students to come up with their own ideas about research.

There was some variation in the way the actual research question was decided upon, which was mainly dependent on the number of suggestions the students came up with. In Blue and Green groups the students came up with a number of conflicting research questions, and the final research question was chosen through a process of negotiation. In the case of Blue group the Delphi technique (Schmidt, 1997) was used. In the other groups students needed to be prompted to come up with a research question: in Orange group the faculty member guided students through the process by leading a discussion on what makes a good research question; Black group used a brainstorming technique; in Red group faculty member talked about how to develop a research question, gave the student prompts and asked them to write down two questions for each prompt.

Four out of the five groups opted for a questionnaire survey, though other research methods were considered. However, the constraints of time and of the University's Human Ethics requirements meant that many alternative approaches were impractical. Green group came up with an original approach and developed a two-stage research strategy. They used a group brainstorming session to identify facilitators and inhibitors of group learning, and then carried out a group interview.

When it came to analysing the data there was quite a difference in emphasis between different faculty, which reflects each individual's personal approach to research. Though all groups covered the basics, one concentrated more on different statistical techniques; another on the frameworks that are commonly used in IS research, another concentrated on coding techniques. Two groups concentrated more on a discussion of ethical issues. All group leaders observed that the timeframe to develop their analysis of the data was very tight, so it was interesting to see how different faculty decided on the research issues which they regarded as critical.

Four of the five groups came out with some usable results for their research. For Blue group the research produced unexpected findings when survey respondents reported no negative impacts of communications technologies. Orange group felt it was of more value to discuss the overall concepts behind the research rather than spend time on computing the results of their survey.

Some groups had put more emphasis on the research product, in terms of putting their efforts into trying to come up with an answer to the research question they had posed. Other groups had put more weight on exploring the stages of the research process itself. This could be seen in the final presentations, the groups that had concentrated more on product reported on the findings of their research, whereas the groups that had more of a process orientation reflected more on the path they had taken to get to those findings. What came out strongly was that, regardless of whether a group had concentrated on product or process, significant learning had taken place.

The time spent on the initial planning and the feedback mechanism during the camp itself ensured that all groups where progressing similarly. The emphasis was firmly on discovery learning, and encouraging students to develop their own ideas about research. However, the design of the Discovery Camp did allow for some individual variation in rhythm as faculty adapted the requirements of each session to the needs and aspirations of their own particular group, and also brought along their own particular research enthusiasms.

\section{Discussion and Conclusion}

From a student perspective, the Discovery Camp appears to have been very successful. Students "Really enjoyed it!"

Section 2 set out the objectives of the event and the level of their achievement was assessed using a feedback questionnaire at the end of the event. The results showed that the primary objective, increasing student's interest in graduate studies, was achieved (6.5 of 7). 
"Enjoyed the insight into the BCA Honours programme and how this operates - enough to conceptualise its value, workload and characteristics"

"The honours programme - have become interested when previously I was not so keen"

Also, students reported that the camp strengthened their interest in Information Systems (6.3 of 7). This indicates meeting of the secondary objective of committing students to information management studies rather than other areas of their degrees. The objectives translated into the event having to be both enjoyable and challenging (Section 2). Participants report that this goal was met, with a well organized (6.7 of 7), enjoyable (6.3 of 7) but also intellectually stimulating (6.4 of 7) event.

\section{"Really enjoyed the socializing with others from different areas, lecturers and research interests - finding out what makes them tick."}

Finally, in terms of planning for future events, participants reported that they would recommend the event to their peers (6.4 of 7). Word of the Discovery Camp has spread amongst the undergraduates and there has been a heightened interest in whatever other Talent Fostering events/programmes might be offered.

However, some minor challenges were encountered, mostly of organizational nature. For example, a few participants suggested that the event start later than 9 a.m. This might indicate that the psychological separation between the Discovery Camp and the regular semester was not as strong as hoped for. A second issue related to the timing of the event was the reduced bus schedule on Saturdays, which presented problems to some participants. Finally, the information that was provided to participants prior to the camp needs to be improved.

In terms of recruiting graduate students, the camp has so far only proved moderately successful. However, when initiating the event, it was clear that talent fostering is not a one-off event. Specifically, Gandz (2006) suggests that talent fostering is best thought of as a pipeline that must be primed and should not be interrupted. Indeed, many discovery camp participants were in their second year of enrolment in the school's programme, and will only be able to consider graduate studies in a year's time.

From a faculty perspective, the Discovery Camp was a success. Students were forthcoming and participative and generally very responsive. That is always rewarding for an academic. It also provided an opportunity to get to know at least some students better. Subsequent contact with various students has been maintained. All participating faculty members were unanimous in supporting the idea of the Discovery Camp becoming an annual event - and others have displayed an interest in being involved in the future.

\section{References}

Barkley, E.F., Cross, K.P. \& Major, C.H. (2005). Collaborative learning techniques: A handbook for College Faculty ( ${ }^{\text {st }}$ ed.). San Francisco, CA: Jossey-Bass Publishers

Brown, J.S. (2000). Growing up digital: How the Web changes work, education and the ways people learn. Change, (March/April), 11-20.

Chickering, A.W. \& Ehrmann, S.C. (1996). Implementing the seven principles: Technology as lever. AAHE Bulletin, (October), 3-6.

Gandz, J. (2006). Talent development: The architecture of a talent pipeline that works. Ivey Business Journal Online, (January/February), 1-4.

Ketteridge, S., Marshall, S. \& Fry, H. (2002). The effective academic: A handbook for enhanced academic practice. London: Kogan Page. 
Ramsden, P. (2003). Learning and teaching in higher education ( $2^{\text {nd }}$ ed.). London: Routledge Falmer.

Schmidt, R. C. (1997). Managing Delphi surveys using nonparametric statistical techniques. Decision Sciences, 28(3), 763-774.

\section{Biographies}

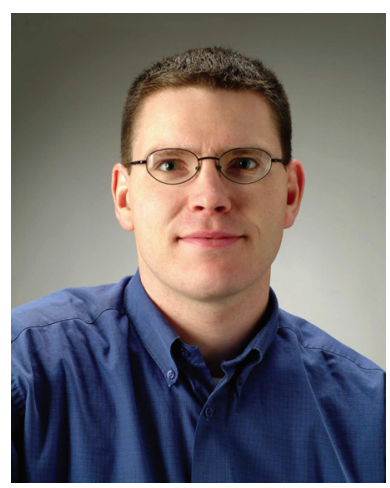

Joerg Evermann received his $\mathrm{PhD}$ in MIS from the University of British Columbia in Vancouver, Canada and is a faculty member with the Victoria University of Wellington since 2003. He has industry experience as an ERP consultant. His research interests are in conceptual modeling and knowledge representation.

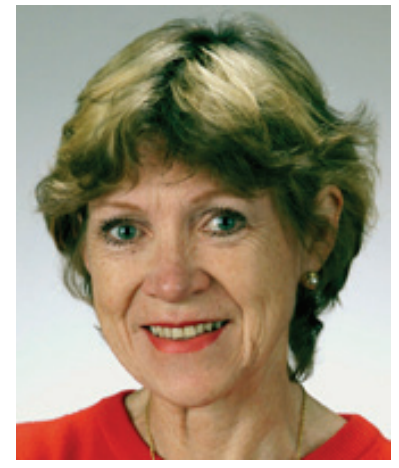

Val Hooper has been lecturing for nearly two decades in diverse areas including Information Systems Management; Electronic commerce; Brand Management; Economics; Strategic Management; Marketing Management; and Research Methodology. In 2004 she was awarded the Victoria University of Wellington Teaching Excellence Award. She has also practiced widely as a management and specialist consultant with clients emanating from a range of industries including industrial engineering, agricultural engineering, a university consortium, a national health research council, and the tobacco industry.

Val obtained her $\mathrm{PhD}$ in Information Systems from Victoria University, and her current research focuses on the strategic alignment between IS and marketing, and the impact of that alignment on marketing performance and business performance. Further research interests include all areas pertaining to the strategic application of IS to business performance, to e-commerce, and to m-commerce; as well as the application of IS in tertiary education.

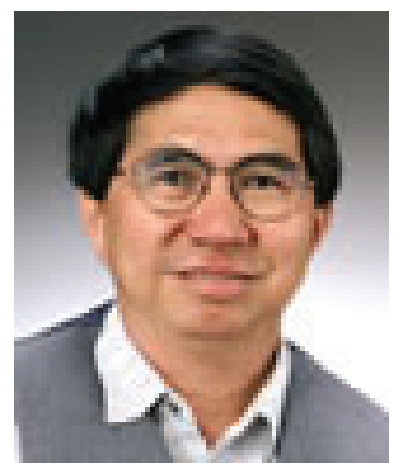

Dr Pak Yoong is an Associate Professor and Director of the Doctoral Programme in Information Systems and E-commerce with the School of Information Management at Victoria University of Wellington. During the last decade he has worked with numerous New Zealand and global organisations in setting up Communities of Practice (CoP) and Knowledge Networks involving senior public servants, professional facilitators, researchers, social workers, systems developers and Helpdesk consultants.

Pak's doctoral students are also researching on various aspects of online knowledge sharing and communities of practice including (a) online knowledge sharing and leadership development among pre-school education professionals (b) online peer-to-peer consulting in a virtual organisation (c) online knowledge transfer between older and younger workers, (d) the role of online CoP to support professional development among teachers of ICT. 
Pak also pioneered the use of 'grounded action learning' method a combination of grounded theory and action learning in ICT research. The approach allows firstly the generation of research data via action learning, and subsequently the development of emerging theories using grounded theory. Pak believes this research approach is especially useful when studying the application of emerging information technologies in organisations, such as knowledge management systems, ecommerce and so on.

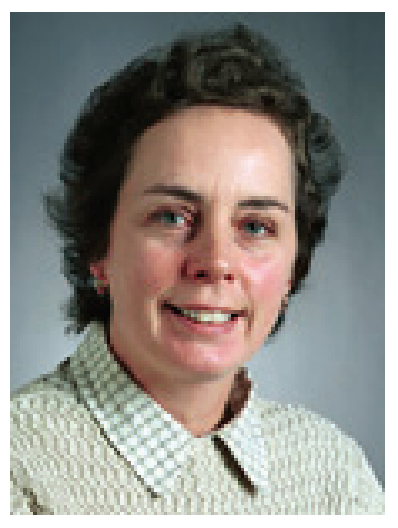

Janet Toland is a Senior Lecturer in Information Systems/Ecommerce and a PhD Candidate at Victoria University of Wellington. Janet teaches in the areas of information systems management, business systems analysis and research methods. Janet's PhD research is assessing the role that information and communications technologies play in regional development in New Zealand. Other research interests include the use of ICT in developing countries particularly in the South Pacific, and the use of computer mediated communication in tertiary education.

Eusebio Scornavacca [Biography not available] 